\title{
Investigations on Microcrystalline Silicon Films for Solar Cell Application
}

\author{
Hae-Sook Hwang, Min Gyu Park, ${ }^{\dagger}$ Hyun Ruh, ${ }^{\dagger}$ and Hyunung Yu ${ }^{\dagger}, *$ \\ Department of Applied Chemistry, Daejon University, Daejeon 300-716, Korea \\ ${ }^{\dagger}$ Korea Research Institute of Standards and Science, Daejeon 305-600, Korea. ${ }^{*}$ E-mail: peacewithu@kriss.re.kr \\ Received April 27, 2010, Accepted August 27, 2010
}

\begin{abstract}
Hydrogenated microcrystalline silicon ( $\mu \mathrm{c}-\mathrm{Si}: \mathrm{H}$ ) thin film for solar cells is prepared by plasma-enhanced chemical vapor deposition and physical properties of the $\mu \mathrm{c}-\mathrm{Si}: \mathrm{H} \mathrm{p}$-layer has been investigated. With respect to stable efficiency, this film is expected to surpass the performance of conventional amorphous silicon based solar cells and very soon be a close competitor to other thin film photovoltaic materials. Silicon in various structural forms has a direct effect on the efficiency of solar cell devices with different electron mobility and photon conversion. A Raman microscope is adopted to study the degree of crystallinity of Si film by analyzing the integrated intensity peaks at 480, 510 and $520 \mathrm{~cm}^{-1}$, which corresponds to the amorphous phase (a-Si:H), microcrystalline $(\mu \mathrm{c}-\mathrm{Si}: \mathrm{H})$ and large crystals $(\mathrm{c}-\mathrm{Si})$, respectively. The crystal volume fraction is calculated from the ratio of the crystalline and the amorphous phase. The results are compared with high-resolution transmission electron microscopy (HR-TEM) for the determination of crystallinity factor. Optical properties such as refractive index, extinction coefficient, and band gap are studied with reflectance spectra.
\end{abstract}

Key Words: Hydrogenated silicon, Nanocrystalline silicone, Photovoltaic solar cell, Silicon film, Raman crystallinity

\section{Introduction}

Various silicon materials with different structures have been studied for electron mobility, photon conversion and fabrication. The diverse silicon forms for solar cells are mixed and heterogeneously grown to improve the efficiency for absorbing light and operating lifetime. Amorphous silicon (a-Si) has defects with dangling bond which is broken from the well-ordered $\mathrm{sp}^{3}$ symmetry of silicon crystal (c-Si). These defects lead to undesirable electrical behavior, in which electrons recombine rather than contribute to the electrical current. To reduce the disorder and increase electric conductivity, the dangling bonds are often passivated by hydrogen (a-Si:H) (Figure 1).

Among many Si materials in thin film solar cells, hydrogenated microcrystalline silicon $(\mu \mathrm{c}-\mathrm{Si}: \mathrm{H})$ thin film has attracted great interest for their potential applications due to low expense, reliable output even at low light levels, absorption at a broad spectrum of light, no feedstock limitation. ${ }^{1-5}$ The $\mu \mathrm{c}-\mathrm{Si}: \mathrm{H}$ has a several nanometer-sized grains of Si crystalline within a-Si:H domain plus grain boundaries, which increase the absorption of sunlight and electron mobility. This also has a good resistance to light-induced degradation under prolonged light exposure. ${ }^{6}$ The films are usually prepared from silane gas with optimizing temperature, pressure, hydrogen dilution, and other

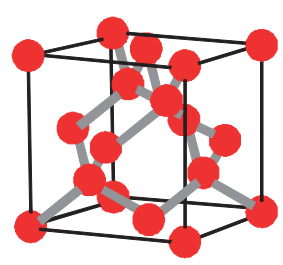

c-Si

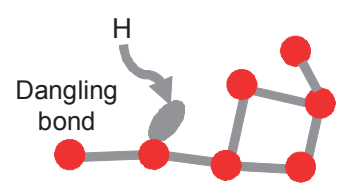

a-Si:H
Figure 1. Crystal structures of c-Si and a-Si:H. parameters for deposition conditions. ${ }^{7,8}$ By increasing the silane concentration in the hydrogen gas, the microstructure of material can be changed from highly crystalline to amorphous. ${ }^{9,10}$ Using plasma-enhanced chemical vapor deposition (PECVD) the intrinsic layer can be prepared near the transition from crystalline to amorphous growth. ${ }^{4,11-14}$

During the fabrication process, the rapid and reliable characterization is very important to monitor the structure and crystallinity of the Si thin film that has inevitable defects in the Si substrate. ${ }^{9}$ Here, Raman instrument is very powerful to analyze the transition region from a-Si:H to $\mu \mathrm{c}-\mathrm{Si}: \mathrm{H}$, thus for the calculation of the crystalline volume fraction. ${ }^{4,14-16}$ Complementary studies using Raman spectra and high-resolution transmission electron microscopy (HR-TEM) reveal the distribution of the crystal size and the degree of crystallinity.

A non-destructive reflectance spectroscopy delivers the optical properties such as refractive index, extinction coefficient, and thickness in silicon films. When the film thickness is uniform, the reflected lights from ultraviolet to visible region show specific spectra shape such as sine-wave pattern from the interference of the film depending on thickness and optical constants. Sample thickness, refractive index $(n)$ and extinction coefficient $(k)$ can be determined from the reflectance spectrum. The accuracy of the thickness measurement depends on the fitting method and the optical $n$ and $k$ values of underlying layers in the process. From the absorption coefficient, a band gap energy also can be determined where the absorbing layer control for high efficiency is important in solar cells. ${ }^{14,17}$

\section{Experimental}

An intrinsic layer is prepared with PECVD method near the transition from crystalline to amorphous growth according to the previous reports. ${ }^{2,9}$ The intrinsic structure is formed within 
a-Si:H absorbing layer onto the glass substrate. This sample of yellow-reddish color is simply loaded into stage for optical measurement such as Raman or reflectance spectra.

The home-made confocal Raman microscope is utilized for a determination of the crystallinity of the Si thin film. The details are described elsewhere. ${ }^{18}$ Briefly, a He-Ne laser $(633 \mathrm{~nm})$ beam of $4 \mathrm{~mW}$ is delivered to a microscope (Zeiss, Axiovert40CFL) via a single-mode optical fiber after a narrow-band interference filter. The Rayleigh scattered light is removed using a Raman filter (Semrock, RazorEdge Raman Filter, LP02633RE) and the Raman signal is delivered into a spectrograph (SpectraPro, 2300i) equipped with a TE-cooled CCD (Princeton Instruments, PIXIS: 100B).

The distribution of crystal size has been confirmed with HRTEM (FEI-Model : TECNAI G ${ }^{2}$ ). The accelerating voltage is kept at $300 \mathrm{kV}$ and twenty five images are taken at multiple locations.

For a spectroscopic reflectance, a ray of light, which is emitted from the Tungsten-Halogen lamp is guided into the thin film on the stage through a microscopic objective lens. The depth or the thickness of the layer is determined with a Swanepoel method by a Bruggemann Effective Medium Approximation (EMA) model consisting of $20 \%$ voids and $80 \%$ of the underlying uc-Si:H material with $n, k$ and the reflectance spectra.

\section{Results and Discussion}

Figure 2 shows spherical shapes of crystallites (red circle in Figure $2 \mathrm{a}$ and $2 \mathrm{~b}$ ) embedded within $\mathrm{a}-\mathrm{Si}: \mathrm{H}$ domain for two
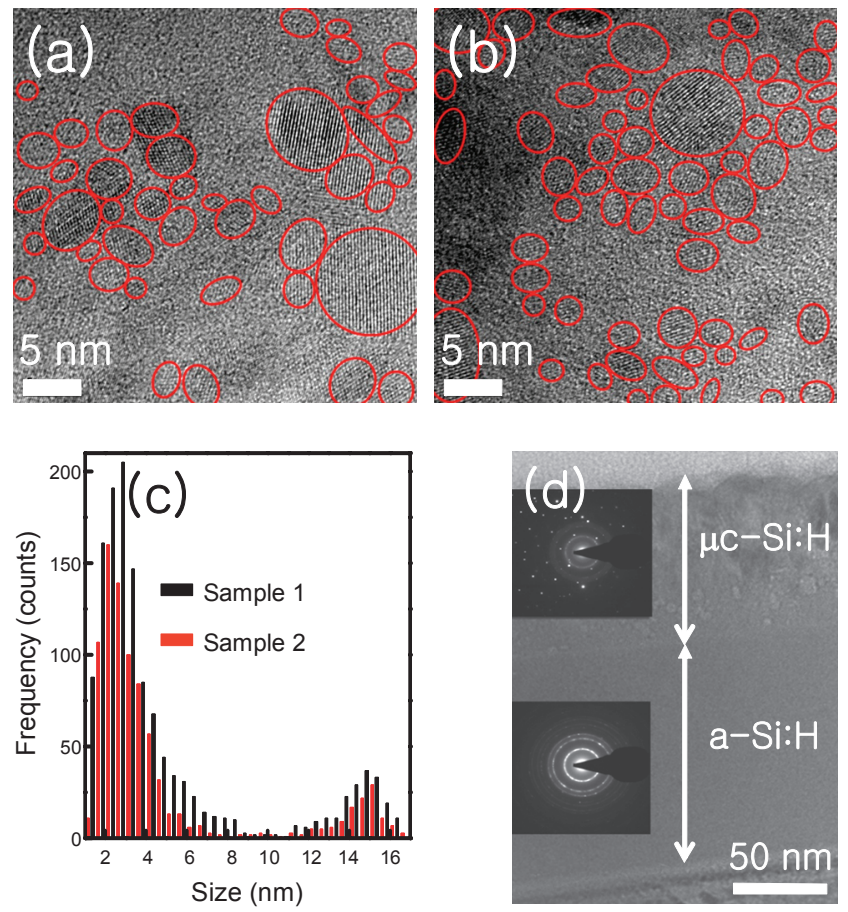

Figure 2. Representative HR-TEM images of (a) sample 1 and (b) sample 2 showing the spherical morphology of the $\mu \mathrm{c}-\mathrm{Si}: \mathrm{H}$ within the thin Si films. (c) Distribution histogram of nanocrystals statistically analyzed from 25 images of HR-TEM. (d) Cross sectional TEM projection of the sample with $\{111\}$ surfaces. Only Si atoms cluster are revealed in the images. samples and their distribution histogram (Figure 2c). Crosssectional TEM image clearly presents a $\mu \mathrm{c}-\mathrm{Si}: \mathrm{H}$ layer deposited on a-Si:H structure (Figure 2d). From the glass substrate, the initial growth region (a-Si:H bottom layer) is followed by a $\mu \mathrm{c}-$ Si:H phase. Many lattice points are observed in $\mu \mathrm{c}-\mathrm{Si}: \mathrm{H}$ domain, while slight fractions are monitored in a-Si:H layer (inset), indicating nanocrystals are still mixed in amorphous region. The film thickness is estimated to be $230 \mathrm{~nm}$, in which a-Si:H/ $\mathrm{cc}-$ $\mathrm{Si}: H$ transition occurs by a silane concentration change during deposition process. ${ }^{15}$

Information about the size distribution of the nanocrystals from the HR-TEM analysis is more important to understand the quantum efficiency and stability of Si films. HR-TEM image reveals that these nanoparticles are grown as $\mu \mathrm{c}-\mathrm{Si}: \mathrm{H}$ with faceted morphology presenting compressive spherical shape. The d-spacing of $0.313 \mathrm{~nm}$, which corresponds to the [111], planes of the cubic Si phase view along to [111] direction according to JCPDS card number 27-1402. We observe smaller lattice distances from $0.29 \mathrm{~nm}$ to $0.30 \mathrm{~nm}$ than d-spacing of $0.313 \mathrm{~nm}$, because the small crystallite has the compressive stress in its 2-dimensional projection. In the case of the samples with [111] surfaces only Si atoms cluster are revealed in the HR-TEM images.

For crystallite-size evaluation, 25 images are taken from HRTEM micrographs for each sample. Large grain more than 10 $\mathrm{nm}$ can be assigned to the large crystal (c-Si) while small one to the microcrystalline ( $\mu \mathrm{c}-\mathrm{Si}: \mathrm{H})$. The histogram of crystal-size distribution tells that the average size increases as the distribution becomes wider. We have observed the smaller lattice distance and the compressive spherical shape in HR-TEM. Sample 1 has more population of $\mu \mathrm{c}-\mathrm{Si}: \mathrm{H}$ with a maximum at $3.5 \mathrm{~nm}$ and c-Si species while sample 2 has a smaller size crystalline around $2.5 \mathrm{~nm}$.

Figure 3 illustrate the Raman spectra from 430 to $580 \mathrm{~cm}^{-1}$ of two silicon films obtained with the Raman microscope using a $50 \times$ objective. There are extra distincitive peaks at around 640,880 , and $2000 \mathrm{~cm}^{-1}$, corresponding $\mathrm{Si}-\mathrm{H}$ wagging mode, bending scissor mode, and stretching mode. ${ }^{13}$ But we will not discuss the analysis of these bands since this is out of our interest for the determination of Si crystallinity. The sharp phonon peak near $520 \mathrm{~cm}^{-1}$ indicates that the silicon material is c-Si structure. The line width and shift of the $\mu \mathrm{c}-\mathrm{Si}: \mathrm{H}$ band in silicon films indicates the size of the nano-crystals. ${ }^{13,15}$ Information about the size of the nanocrystals in the silicon skeleton is important to understand the role of quantum confinement of electrons. Information of crystalline volume fraction of the material is useful to monitor for stability of the films that are light soaked at different energies and wavelengths. ${ }^{15}$ The Raman microscope characterizes the structural properties of the crystal size and the degree of crystalline silicon films. The spectrum consists of three main peaks, one centered at around $480 \mathrm{~cm}^{-1}$, the other centered at around 510 and $520 \mathrm{~cm}^{-1}$. The former peak is attributed to the a-Si:H portion of film, while the latter peak to the crystalline portion ( $\mu \mathrm{c}-\mathrm{Si}: \mathrm{H}$ and c-Si) of film. ${ }^{15,16}$ The compressive stress of crystallite affects a mode of a-Si:H at $520 \mathrm{~cm}^{-1}$ by a red shift. The bandwidth and shift of the $\mu \mathrm{c}-\mathrm{Si}: \mathrm{H}$ peak indicates the size of the nanocrystals (as the crystallite size increases the bandwidth becomes broader or shifts to lower 
(a)

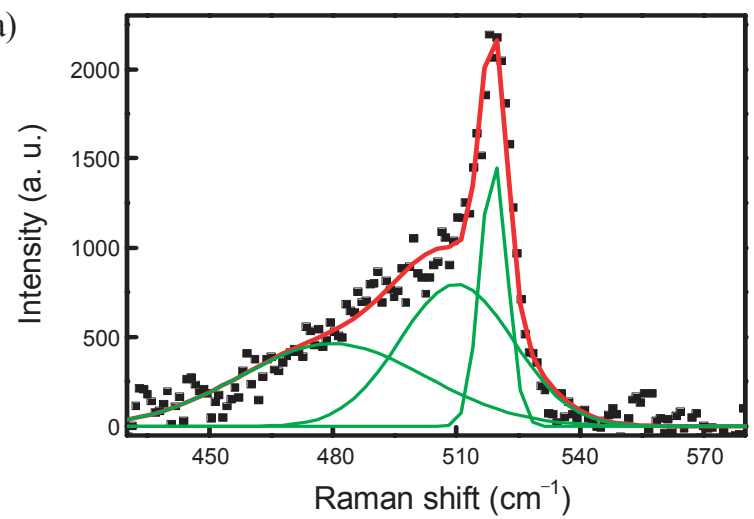

(b)

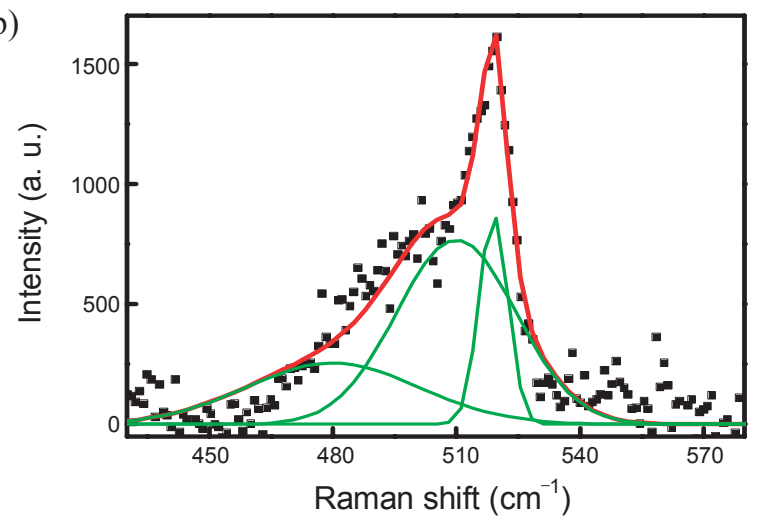

Figure 3. Raman spectra of a mixed-phase silicon film excited at 633 $\mathrm{nm}$. The three main peaks, large crystalline phase $\left(\mathrm{c}-\mathrm{Si}, 520 \mathrm{~cm}^{-1}\right)$, small crystalline phase $\left(\mu \mathrm{c}-\mathrm{Si}: \mathrm{H}, 510 \mathrm{~cm}^{-1}\right)$, and amorphous phase (a-Si:H, $480 \mathrm{~cm}^{-1}$ ) are deconvoluted with three Gaussian functions. The crystallinity factor can be calculated from the ratio of each integrated intensity.

energy).

The Raman crystallinity is calculated as $X_{\mathrm{c}}$ given by ${ }^{13,15,16}$

$$
X_{\mathrm{c}}=\left(I_{510}+I_{520}\right) /\left(I_{480}+I_{510}+I_{520}\right), X_{\text {amorphous }}=1-X_{\mathrm{c}}
$$

where $I_{i}$ denotes an integrated intensity at $i \mathrm{~cm}^{-1}$, and $\left(I_{510}+\right.$ $\left.I_{520}\right)$ is equal to the volume fraction of the crystalline phase.

The crystallinity and other optical properties are summarized in Table 1. Our fabricated solar cell displays the onset of the $\mu \mathrm{c}-\mathrm{Si}: \mathrm{H}$ growth with $X_{\mathrm{c}}=61$ and $66 \%$. Each film has a mixture of a-Si:H and $\mu \mathrm{c}-\mathrm{Si}: \mathrm{H}$. It is apparent that sample 2 has less a-Si content than sample 1 (fitting curves in Figure $3 a$ and $3 b$ ). From

Table 1. The optical properties of $\mathrm{Si}$ thin film such as refractive index $(n)$, extinction coefficient $(k)$ at $633 \mathrm{~nm}$, and band gap determined by thickness of silicon films from reflectance data in Figure 4

\begin{tabular}{cccccc}
\hline Sample Substrate & $\begin{array}{c}\text { Thickness } \\
(\mathrm{nm})\end{array}$ & $\begin{array}{c}n(633 \mathrm{~nm}) \\
k(633 \mathrm{~nm})\end{array}$ & $\begin{array}{c}\text { Band Gap } \\
(\mathrm{eV})\end{array}$ & $\begin{array}{c}\text { Crystallinity, } \\
X_{\mathrm{c}}\end{array}$ \\
\hline \multirow{2}{*}{$\# 1$} & Glass & 243 & $\begin{array}{c}3.68 \\
0.029\end{array}$ & 2.08 & 0.61 \\
\multirow{2}{*}{$\# 2$} & Glass & 234 & $\begin{array}{c}3.86 \\
0.030\end{array}$ & 1.96 & 0.66 \\
\hline
\end{tabular}

(a)

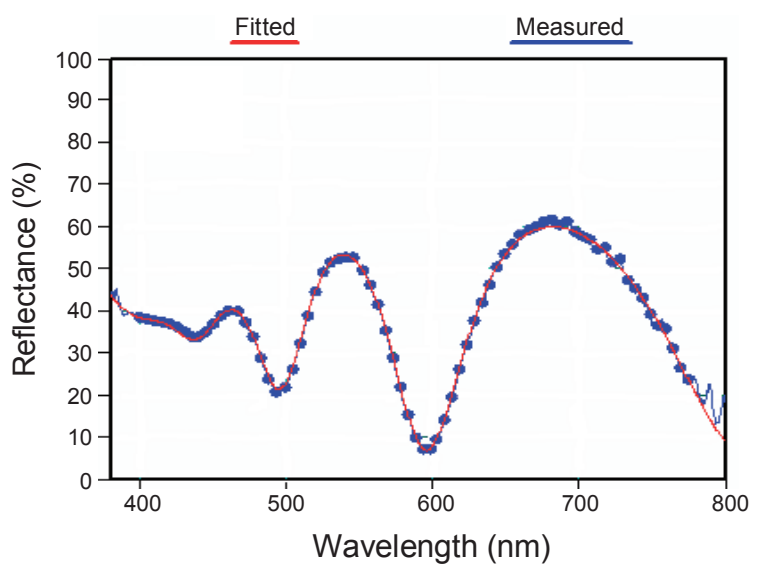

(b)

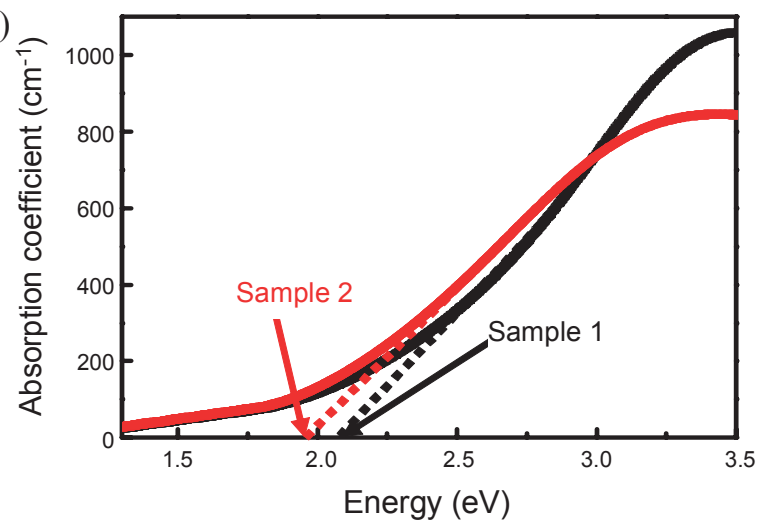

Figure 4. (a) Spectroscopic reflectance and fitted result of sample. (b) Absorption Spectra of Si thin film vs Energy (eV).

Raman spectra, the sample 2 has more crystallinity factor as the $X_{\mathrm{c}}$ are determined from the ratio between amorphous and crystalline. The difference is that sample 2 has more population of small-sized $(2.5 \mathrm{~nm}) \mu \mathrm{c}-\mathrm{Si}: \mathrm{H}$ and much less density of a-Si than sample 1.

Figure $4 \mathrm{a}$ shows a reflectance spectrum and fitted line of sample 1, which shape looks like sine-wave with successive maxima and minima. This is caused by interference effects of Fresnel reflection when film thickness is uniform. Sample thickness, refractive index $(n)$ and extinction coefficient $(k)$ can be calculated (Table 1) from the simple reflectance spectrum using the Swanepoel method. ${ }^{19}$ This method is applied to thin films deposited on transparent substrates. The thickness is measured around $240 \mathrm{~nm}$ for both samples, which gives a good correlation to the value from TEM cross-section image. The $n$ value of sample 1 is slightly lower than that of sample 2. As the $n$ of large silicon crystalline $(n=3.45)$ is smaller than hydrogenated silicon phase $(n=3.73),{ }^{20,21}$ high concentration of $\mu \mathrm{c}-\mathrm{Si}: \mathrm{H}$ species relative to c-Si in sample 2 gives a higher $n$ value than sample 1.

The optical band gap can be evaluated using the Tauc-Lorentz's relation ${ }^{13,22}$ with the absorption coefficient $(\alpha)$ and the incident photon for an indirect semiconductor given by:

$$
(\alpha h v)^{1 / 2} \propto\left(h v-E_{g}\right)
$$


From the intersection point of linear fit with the abscissa (Figure $4 \mathrm{~b}$ ), a band gap ( $\mathrm{E}_{\mathrm{g}}$ ) of 1.96 to $2.08 \mathrm{eV}$ is acquired. The optical $\mathrm{E}_{\mathrm{g}}$ also decreases with an increment of $k$ value. The results indicate that sample 2 with more $\mu \mathrm{c}-\mathrm{Si}: \mathrm{H}$ population can absorb more light than sample 1 .

From sample 1 to sample 2, the intrinsic absorbing layer is investigated near the transition from crystalline to amorphous growth. The $\mu \mathrm{c}-\mathrm{Si}: \mathrm{H}$ has from $3.5 \mathrm{~nm}$ to $2.5 \mathrm{~nm}$-sized grains of Si crystalline within the amorphous phase plus grain boundaries, which increase the absorption efficiency of photons.

We believe the shape and magnitude of Raman bands are useful when optimizing temperature, pressure, hydrogen dilution, and other parameters for deposition conditions. They are also useful to monitor for stability of the films that are light soaked at different energies and wavelengths.

\section{Conclusion}

We have investigated the intrinsic layer on glass. The reliable structure analysis of $\mu \mathrm{c}-\mathrm{Si}: \mathrm{H}$ was confirmed by combining the Raman Spectra with HR-TEM images. Distribution and structural characterization via a Raman microscope can be achieved as a bulk probe at a few micron scales. HR-TEM as a microprobe is also useful for the analysis of the Si thin film. The observed crystal-size distribution in HR-TEM images is strongly correlated with the intensity variations for Raman signal. Sample 1 shows most of $\mu \mathrm{c}-\mathrm{Si}: \mathrm{H}$ with a maximum at $3.5 \mathrm{~nm}$ with a regular strong intensity while sample 2 has a crystalline around $2.5 \mathrm{~nm}$. However, sample 2 gives a higher crystallinity factor than sample 1 because of more population of $\mu \mathrm{c}-\mathrm{Si}: \mathrm{H}$.

In the Raman scattering and spectroscopic reflectance, the optical properties, such as refractive index, extinction coefficient, and thickness in Si films are also strongly correlated evidence with crystal sizes and distributions. Increasing the $\mu \mathrm{c}-\mathrm{Si}: \mathrm{H}$ results in higher $n$ and $k$, thus increases the absorption of photons for $\mu \mathrm{c}-\mathrm{Si}: \mathrm{H}$ absorber layer.

Acknowledgments. This work is supported by the Korea Research Council of Fundamental Science and Technology (KRCF) through the project of 'Development of Characterization Techniques for Nano-materials Safety'.

\section{References}

1. Berginski, M.; Hupkes, J.; Gordijn, A.; Reetz, W.; Watjen, T.; Rech, B.; Wuttig, M. Solar Energy Mater. Solar Cells 2008, 92, 1037.

2. Yoshioka, K.; Sameshima, T.; Sano, N. Solid-State Electronics 2008, 52, 359.

3. Jung, Y. C.; Kim, D. S.; Hong, B. H.; Cho, K. H.; Hwang, S. W.; Ahn, D.; Yu, Y. S.; Choi, B. H. J. Nanosci. Nanotechnol. 2008, 8, 5009 .

4. Takagi, T.; Ueda, M.; Ito, N.; Watabe, Y.; Kondo, M. Japan. J. Appl. Phys. 2006, 45, 4003 .

5. Kelzenberg, M. D.; Turner-Evans, D. B.; Kayes, B. M.; Filler, M. A.; Putnam, M. C.; Lewis, N. S.; Atwater, H. A. Nano Lett. 2007, 8,710 .

6. Chowdhury, A.; Mukhopadhyay, S.; Ray, S. Solar Energy Mater. Solar Cells 2009, 93, 597.

7. Terasa, R.; Albert, M.; Bartha, J. W.; Roessler, T.; Abramov, A. S.; Kosarev, A. I.; Kuduyarova, V. K.; Vinogradov, A. Thin Solid Films 2003, 427, 270.

8. Nuruddin, A.; Abelson, J. R. Thin Solid Films 2001, 394, 49.

9. Li, S.-B.; Wu, Z.-M.; Jiang, Y.-D.; Yu, J.-S.; Li, W.; Liao, N.-M. J. Appl. Phys. 2008, 41, 5 .

10. Strahm, B.; Howling, A. A.; Sansonnens, L.; Hollenstein, C. J. Vac. Sci. Technol. A 2007, 25, 1198.

11. Buitrago, R. H.; Risso, G. A.; Cutrera, M.; Battioni, M.; de Bernardez, L.; Schmidtm, J. A.; Arce, R. D.; Koropecki, R. R. Intern. J. Hydrogen Energy 2008, 33, 3522.

12. Zhang, X. D.; Zhang, F. R.; Amanatides, E.; Mataras, D.; Zhao, Y. Thin Solid Films 2008, 516, 6912.

13. Myong, S. Y.; Sriprapha, K.; Yashiki, Y.; Miyajima, S.; Yamada, A.; Konagai, M. Solar Energy Mater. Solar Cells 2008, 639, 92.

14. Acciarria, M.; Binettia, S.; Bollania, M.; Comottia, A.; Fumagallia, L.; Pizzinia, S.; von Kanel, H. Solar Energy Mater. Solar Cells 2005, 87,11

15. Droz, C.; Vallat-Sauvain, E.; Bailat, J.; Feitknecht, L.; Meier, J.; Shah, A. Solar Energy Mater. Solar Cells 2004, 81, 61.

16. Voutsas, A. T.; Hatalis, M. K.; Boyce, J.; Chiang, A. J. Appl. Phys. 1995, 78, 6999.

17. Li, H.; Franken, R. H.; Stolk, R. L.; van der Werf, C. H. M.; Rath, J. K.; Schropp, R. E. I. Thin Solid Films 2008, 516, 755.

18. Lee, H.-O.; Kim, E.-M.; Yu, H.; Jung, J.-S.; Chae, W.-S. Nanotechnol. 2009, 20, 325604.

19. Ilker, A. Y.; Tolunay, H. Turk. J. Phys. 2001, 25, 215.

20. de Dood, M. J. A.; Polman, A.; Zijlstra, T.; van der Drift, E. W. J. M. J. Appl. Phys. 2002, 92, 649.

21. Reitano, R.; Grimaldi, M. G.; Baeri, P.; Borghesi, A.; Sassella, A. Thin Solid Films 1993, 233, 203.

22. Pandey, V.; Mehta, N.; Tripathi, S. K.; Kumar, A. J. Optoelectron. Adv. Mater. 2005, 7, 2641. 